\title{
MULTICULTURAL ASPECTS OF SUPERVISION: CONSIDERATIONS FOR SOUTH AFRICAN SUPERVISORS IN THE HELPING PROFESSIONS
}

\section{A Kagee}

\section{MULTICULTURAL ASPECTS OF SUPERVISION IN POST-APARTHEID SOUTH AFRICA}

Clinical supervision in psychology and social work is challenged with addressing the various cultural, social and political factors that affect therapeutic and supervisory relationships. In the context of present-day South Africa with its emphasis on recruiting supervisees into the helping professions from diverse racial and ethnic backgrounds, questions of race, ethnicity and culture in clinical supervision have become of considerable importance. This paper examines the literature pertinent to supervision and presents a theoretical framework for conceptualising the multicultural development of supervisors and supervisees with a specific emphasis on the South African context. It highlights some of the potential problems that might arise in supervisory relationships in which the supervisor and supervisee are racially disparate and outlines recommendations for clinicians to consider in their practice. Most of the research on inter-racial clinical supervision has been conducted in the United States and other countries where multiculturalism is part of the national landscape. This article uses this international literature and applies it to the present post-apartheid context.

Multicultural supervision has been defined as a supervisory relationship in which the supervisor and supervisee are from culturally different groups (Leong \& Wagner, 1994). Indeed, race and ethnicity are salient features of a multicultural supervisory exchange (Fukuyama, 1994). It has been argued that the term "multicultural" is preferable to "cross-cultural" (Bernard, 1994). The latter implies the operation of a single cultural variable in a supervisory dyad, while the former emphasises the plurality of factors that form part of a multicultural exchange, namely race, ethnicity, gender, sexual orientation, geographical origin, disability status and language preference. Thus, a cross-racial interaction that is also cross-gender is multicultural in nature. Indeed, there may be instances in which race or ethnicity may be a secondary cultural variable if, say, sexual orientation or disability status, is a more salient factor (Bernard, 1994).

There is little research directed at the question of multicultural supervision internationally (Priest, 1994). However, the position that race, ethnicity and culture exert no influence on the dynamics of supervision (Wessler \& Ellis, 1983) appears to be a minority view, as many authors concur that a supervisor-therapist relationship that is not attendant to the interaction of cultural variables may hinder the developmental progress of the therapist, and consequently obstruct the therapeutic progress of the client (Bernard \& Goodyear, 1992; Cook \& Helms, 1988; Gardner, 1980; Guitierrez, 1982; Leong \& Wagner, 1994).

Despite this need for a multicultural perspective to psychotherapy and supervision, many training programmes in the helping professions, such as social work and psychology, do not provide skillbuilding experiences to help staff and students from different cultural, racial and class backgrounds understand or interact with students from historically disadvantaged backgrounds and the problems affecting them. Such observations have been noted in several countries (e.g. Guitierrez, 1982; Priest, 1994; Parker, Valley \& Geary, 1986). The development of multicultural awareness in clinical supervision may be considered from a theoretical perspective, as specific sequences of change and growth between the supervisor and supervisee may invariably occur. The essential theoretical perspectives are now summarised. 


\section{Theoretical models of multicultural supervision}

Various models have been developed to conceptualise the interpersonal dynamics that develop within a multicultural supervisory context (Carney \& Kahn, 1984; Leong \& Wagner, 1994; Priest, 1994). These models identify developmental stages through which both the supervisor and the supervisee proceed in order to reach a level of multicultural awareness that would be optimally therapeutic and educational. Similar to Helms' (1994) stages of racial identity development, the stages of the supervisee and supervisor's racial identity development follow a similar sequence.

In Vasquez and McKinley's (1982) model of supervisees' multicultural identity development, for example, there is a sequential development of racial awareness and sophistication. In Stage One of this model the supervisee's awareness of multiculturalism is minimal and there is no recognition of culture or ethnic background. The role of the supervisor is then to provide a structured and supportive environment, while encouraging an exploration of culture. In the second stage there is a gradual awareness in the supervisee of the discrepancies between cultures, which may result in high emotionality and possible confrontation between the supervisee and the supervisor. Here, the supervisor continues to educate the supervisee, helps him or her recognise the impact of his or her behaviour on clients, and focuses on resolving interpersonal friction in both the supervisory and the therapeutic dyad. In Stage Three integration occurs and a multicultural identity is developed, where the supervisee is able to perceive both cultures in terms of their positive and negative values, and to accept their own part in each culture. This stage also sees a genuine transcendence of race and culture in the supervisee, so that he or she may be prompted to social action to promote equality and social pluralism. Here the supervisor's role is to serve as a consultant rather than an educator. Vasquez and McKinley (1982) further point out that the professions of psychology and social work represent cultures in and of themselves. To this extent supervisees must assimilate into this culture in order to become successful professionals.

As a mode of tracking the multicultural developmental progress of the supervisor, Priest's (1994) model follows a similar pattern. In the first stage of this model the supervisor engages in denial of cultural differences that impact on the supervision or therapeutic relationship. In the second stage he or she may recognise cultural differences that influence these processes, but may not know how to use this new knowledge, and consequently may be overwhelmed with the prospect of learning about and being exposed to other cultures. Similar to the supervisee, the supervisor in the third stage may attempt to identify differences and similarities between and among the respective cultures that impact on the supervisory relationship and may try to identify where he or she fits into the overall schema. In the final stages of this model the supervisor begins to appreciate cultural distinctiveness and identify the thought processes and communication patterns that facilitate supervision and therapy. Hence, equipped with a sophisticated level of cultural awareness, the supervisor is able to supervise effectively, while maintaining a respectful and professional stance towards the supervisee.

\section{Problems in multicultural supervision}

Disputes between the supervisee and the supervisor in terms of their level of development may culminate in potential difficulties in the supervision relationship. Some of these problem areas are now explored. There are at least four levels of interaction that influence the supervisory interaction, namely the client, the therapist, the supervisor and the institution (Pedersen, 1991). Indeed, Bradshaw (1982) notes that in the United States, more often than not, the supervisor is a member of the dominant group, while the client and sometimes the therapist may be ethnic 
minorities. In South Africa, with the relatively few black psychologists and social workers, supervisors are more likely to be White, while supervisees and clients are more likely to be from historically disadvantaged communities. Such configurations are predisposed to a minefield of problematic interactions, if the participants approach their work without locating it within the historical and socio-political context of cultural diversity.

From the perspective of discordant stages of multicultural development between the supervisee and the supervisor (Cook, 1994; Priest, 1994), many interactional difficulties may arise in the supervisory dyad. Leong and Wagner (1994), for example, note that by virtue of the minority supervisee's identification with the helping profession, it is likely that many supervisors in the initial stages of multicultural development may gloss over racial and other cultural differences and mistakenly assume that supervisees identify with them culturally as well. These authors are critical of the myth of sameness that many supervisors embrace. Indeed, Bradshaw notes that, if a White supervisor expresses to a Black supervisee that he or she is not thought of as Black - a phenomenon this author labels "hallucinatory whitening" (Bradshaw, 1982:204) - this may result in the supervisee feeling condescended to and patronised. Such a scenario may be seen as a negation of the supervisee's Black identity, as it is implied that they would be more acceptable if they did not place race on the agenda by "act(ing) Black" (Bradshaw, 1982:205), but instead disavow an integral aspect of their identity. Cook (1994) cautions that if race and culture are ignored in supervision, supervisees may not develop fully integrated professional identities and may consequently experience frustration and anger, if their personal and professional development is not facilitated. Thus, the supervisor and the supervisee are cautioned against "a conspiratorial avoidance of race as resistance, reality or transference issue" (Bradshaw, 1982:204).

At the other extreme, a Black supervisee's cultural disposition may be anthropologised in an exaggerated manner, especially by a supervisor in the middle stages of multicultural development (Priest, 1994), and the supervisee may be asked to form an opinion on every client or issue relevant to the cultural group he or she is supposed to represent (Bradshaw, 1982). Such requests may reflect stereotypical thinking on the part of the supervisor that all members of a cultural group are alike, and may also provoke anxiety in the supervisee, who is called upon to be an instant expert about his or her cultural group.

Bradshaw (1982) cautions that at the same time there exists the danger that the client's progress and the supervisee's development may be compromised if the White supervisor enacts a reaction formation by engaging in overcautious and uncritical behaviour toward the minority supervisee out of fear of being accused of prejudice. On the other hand, the concern about professional development may be abused by the supervisee, who may perceive as racist the supervisor's legitimate questions about her or his work. Bradshaw (1982) notes that the displacement of an internal conflict in supervision to outside situations of racism and prejudice is a difficult defence to confront, since it is often closely tied to a reality.

Vargas (1989, cited in Leong \& Wagner, 1994) regards the over-emphasis of the impact of culture in supervision as cultural counter-transference, since this tendency is also often evoked in the therapist by a culturally different client. This may lead to an overestimation of the influence of culture and a consequent underestimating of the client's problem, leading in turn to misdiagnosis or under-diagnosis (Bernard \& Goodyear, 1992). This position is supported by Bradshaw (1982), who points out the over-compensatory tendency of supervisors and supervisees to conceptualise most of the Black client's problems in terms of racial conflict, thus depriving the client of the opportunity to work through other intrapsychic dilemmas. 
Cook and Helms (1988) report that racially mixed supervisory dyads may be more conflictual than racially homogeneous dyads and that supervisors, especially those at the initial stages of multicultural development, may unwittingly contribute to this conflict. Moreover, these authors found that supervisees' perceptions of their supervision relationships varied according to their race or ethnicity, which may suggest that the supervisor's manner of interacting with them was influenced by these variables. A supervisory relationship between a Black supervisee and a White supervisor may provoke a mutual reaction to each other based on a history of White dominance (Cook, 1994). In such an instance, power and hegemony, sometimes problematic but generally unavoidable attributes of any supervisory relationship (Holloway \& Wolleat, 1994), become the chief variables that govern the exchange. For example, a White supervisor may insist that an ethnic minority supervisee perform according to White-normed counselling theories and practices and may evaluate the supervisee according to these standards (Cook, 1994). Conversely, the supervisee may rebel and struggle with the supervisor in attempting to apply culturally diverse theories and practices and thus receive a poor evaluation. Guiterrez (1982) notes that often supervisors appear superficially flexible, but subsequently become resistant if supervisees introduce non-traditional techniques into their work. Hence, there is a communicated willingness to work with an ethnic minority supervisee as long as it involves no change on the part of the supervisor.

Not surprisingly, such dissonance often provokes scepticism and resentment in the supervisee (Guitierrez, 1982) and this may impact negatively on the supervisory relationship. Bradshaw (1982) notes that a Black supervisee immersed in a largely White environment may feel threatened by such cultural incongruence and may react by perceiving only negative messages from the supervisor and thus respond with either hostility or distance. In turn, the White supervisor may dismiss the supervisee as paranoid, thus validating an initial incorrect hypothesis about Black supervisees and missing the opportunity to understand him or herself and the supervisee.

\section{BLACK SUPERVISORS AND WHITE SUPERVISEES}

For the Black supervisor a plethora of obstacles exist. People of colour who hold positions of authority, such as a supervisory position, often have to contend with the "racism of disbelief in their competence" (Bernard, 1982:164), not only by members of the majority group but also by those from their own culture as well. Bernard (1994) notes that a Black client may distrust the skills of a Black therapist on the assumption that he or she is not good enough to see White clients. In a parallel fashion, a Black supervisee may harbour similar sentiments toward a Black supervisor and may continually challenge his or her directions and guidance on the assumption that the supervisor is not sufficiently skilled to work with White supervisees. Priest (1994) extends this point to White supervisees as well who, at an early stage of multicultural development, may feel that the ethnic minority supervisor's level of expertise is less than adequate when compared to that of a White supervisor. Consequently, the supervisor may continually have to expend energy proving himself or herself in order to deflect racial misconceptions. Conversely, Cook (1994) points out that a Black supervisor may seize the opportunity to wield power over a White supervisee and may overly assert his or her control in the relationship.

Other potential difficulties that may arise in the supervisory context include specific behavioural incongruities mentioned in the literature, such as cultural misunderstandings of personal space and the use of slang (Fukuyama, 1994), different uses of non-verbal behaviour (Ryan \& Hendricks, 1989) and hand gestures (Priest, 1994; Guiterrez, 1982). These considerations pale in comparison with other more serious obstacles such as paternalism, condescension and the abuse of power within the multicultural supervisory dyad. Of course, no discussion of obstacles to sound supervisor-supervisee relationships is complete without identifying racism as a factor in 
supervisory relationships stemming from many decades of living under apartheid. The present historical moment in South Africa, characterised by affirmative action and rules imposed on universities to increase their intake of Black supervisees, may serve to create resentment on the part of conservative and reactionary White supervisors who train Black students, many of whom may not be English first-language speakers.

A multitude of obstacles await supervisees and supervisors from different cultures and racial groups. The challenge is to seek realistic solutions to potential impasses in order to promote opportunities for growth and development in both the supervisor and the supervisee. Some recommendations gleaned from the literature are now tentatively outlined.

\section{RECOMMENDATIONS}

Although differences in perceptions of culture have been emphasised in the above section, it is necessary to note similarities that may be enhanced in the multicultural supervisory exchange. While the supervisee and the supervisor may not share the same ethnic or racial background, the culture of psychotherapy is common to both (Bernard, 1994) after the five years of training during undergraduate and postgraduate studies which is characteristic of South African training programmes. Thus it is possible that the ability to acculturate to the helping profession may minimise the potential for other obstacles to emerge in supervision.

While it is imperative that the supervisory exchange be directed at multicultural questions when they arise (Leong \& Wagner, 1994; Priest, 1994), Bernard notes that supervision is not the arena for the development of multicultural awareness to begin. This author cautions that there is not enough time within the typical supervision relationship for either participant to move from a position of multicultural unawareness to competence. Nonetheless, Leong and Wagner (1994) place the responsibility for addressing multicultural topics on the supervisor, who should ideally serve as a catalyst for the supervisee's exploration of race and ethnicity within himself or herself and with the client. Remington and Da Costa (1989) suggest that such conversations occur early in the relationship, while Leong and Wagner (1994) point out that they should be directed at ushering the supervisee from a level of beginning awareness of multiculturalism to consolidated awareness and finally to a stage of transcendent awareness.

Fukuyama (1994) emphasises that multicultural discussions should occur regardless of the ethnic or cultural backgrounds of the supervisor, the supervisee or the client. Indeed, the supervisor may oversee the developmental advancement of the supervisee (Vasquez \& McKinley, 1982) by providing appropriate levels of challenge and support, thus encouraging the supervisee to embrace a philosophy of psychotherapy that acknowledges pluralism and focuses on sharing multicultural knowledge (Bernard \& Goodyear, 1992; Myers, 1992). Hence, an effective supervisor would ideally facilitate the supervisee's awareness and overcoming of prejudice (Fukuyama, 1994; Gardner, 1980; Priest, 1994), since members of the dominant group who wield social power in society are often unaware of their cultural selves and the biases they unwittingly possess (Bernard, 1994). For such awareness to be developed, Fukuyama (1994) and Priest (1994) suggest that supervisors themselves need to be trained to respect and accept cultural differences, and should thus be more advanced along the developmental continuum than the supervisee in order to guide his or her development.

As Ponterotto and Casas (1987) suggest, supervisors, as well as supervisees should be cognisant of the experiences of ethnic minorities, since these experiences represent the beginning of accurate empathy. Frequent formal and informal contact with members of a racial out-group are imperative (Bernard \& Goodyear, 1992; Parker, Bingham \& Fukuyama, 1985). Such contact may 
enhance supervisors' understanding of Black clients' lives, coping mechanisms, values, and how normality and abnormality are thought of (Gardner, 1980). Such knowledge, according to Gardner (1980), would serve to enhance rapport, eliminate tactless phraseology in therapy and enhance effective communication and comprehension of the social realities of the Black clients.

If stereotypical or prejudicial thinking is evidenced in the supervisee, Priest (1994) suggests that the supervisor candidly address the supervisee's misconceptions to remove inaccurate information and facilitate mutually beneficial experiences for growth in an atmosphere where cultural tolerance and openness are the norm. According to Cook (1994), if supervisors and supervisees engage in forthright here-and-now interactions regarding racial biases in their relationships, they will move towards greater degrees of genuineness and authenticity as clinicians, so that they may critically examine the impact of their racial attitudes on conceptualising their clients' problems.

Gardner (1980) posits that the supervisor may buffer the supervisee through a process of anticipatory preparation, but in order to accomplish this, should possess a reservoir of positive therapeutic experiences with non-traditional patients from which to draw examples. In this way the student may be guided through the process of achieving an optimal understanding of the cultural and social context of the client's problem.

Guiterrez (1982) raises the question of whether Black clinicians should work only with Black clients. She notes that, while such therapy may indeed be effective, the concern is raised that this limitation would merely be another way of relieving the White therapists from the responsibility of engaging professionally with Black populations.

Finally, at an elevated level, Leong and Wagner (1994) favour the role of the supervisor as an agent of organisational change in creating a multicultural institution in order to promote multicultural training. Departments whose staff compliments are diverse may, according to Gardner (1980), provide opportunities for multicultural growth in White students as well as those from minority cultures. Hence both Black and White supervisees may gain an understanding of the common elements of the human psyche that transcend and defy racial and ethnic differences.

\section{CONCLUDING COMMENTS}

Many of the recommendations outlined above show some promise of providing a framework within which to engage in culturally relevant clinical supervision. Indeed, as the multicultural perspective is placed on the agenda in psychological theory and practice, one of the implications is that institutions need to infuse this approach into their training programmes in order to sensitise practitioners to the process of multicultural clinical work. It remains to be empirically demonstrated whether the above recommendations would herald any significant shift in the effectiveness of supervision between supervisees and supervisees who are racially and culturally different from one another. While this paper has focused exclusively on racial differences in supervision, research on other minority groups such as the physically disabled, the elderly and gays and lesbians would have important implications for supervision theory and practice. Also, in South Africa racial and class fault-lines overlap considerably and it is a limitation of this paper that it discusses racial, cultural and ethnic differences without an analysis of how class differences affect clinical supervision. These areas await further investigation.

\section{REFERENCES}

BERNARD, J.M. 1994. Multicultural supervision: A reaction to Leong and Wagner, Cook, Priest and Fukuyama. Counselor Education and Supervision, 34:159-171. 
BERNARD, J.M. \& GOODYEAR, R.K. 1992. Fundamentals of clinical supervision. Boston, MA: Allyn \& Bacon Publishers.

BRADSHAW, W.H., Jr. 1982. Supervision in Black and White: Race as a factor in supervision. In: BIUMENFIELD, M. (ed), Applied supervision in psychotherapy. New York: Grune \& Stratton, 199-220.

CARNEY, C. \& KAHN, K. 1984. Building competencies for effective cross-cultural counseling: A developmental view. The Counseling Psychologist, 12(2):111-119.

COOK, D.A. 1994. Racial identity in supervision. Counselor education and supervision, 34:132-141.

COOK, D.A. \& HELMS, J.E. 1988. Visible racial/ ethnic group supervisees' satisfaction with cross-cultural supervision as predicted by relationship characteristics. Journal of Counseling Psychology, 35:268-274.

FUKUYAMA, M.A. 1994. Critical incidents in multicultural counseling supervision: A phenomenological approach to supervision research. Counselor Education and Supervision, 34:142-151.

GARDNER, L.M.H. 1980. Racial, ethnic, and social class considerations in psychotherapy supervision. In: HESS, A.K. (ed) Psychotherapy supervision: Theory, research and practice. New York: John Wiley \& Sons.

GUITIERREZ, F.J. 1982. Working with minority counselor education students. Counselor Education and Supervision, 21(2):218-226.

HOLLOWAY, E.L. \& WOLLEAT, P.L. 1994. Supervision: The pragmatics of empowerment. Journal of Educational and Psychological Consultation, 5:23-43.

LEONG, F.T.L. \& WAGNER, N.S. 1994. Cross-cultural supervision: What do we know? What do we need to know? Counselor Education and Supervision, 34:117-131.

PARKER, W.W., BINGHAM, R.P. \& FUKUYAMA, M. 1985. Improving cross-cultural effectiveness in counselor supervisees. Counselor Education and Supervision, 24:349-352.

PARKER, W.M., VALLEY, M.M. \& GEARY, C.A. 1986. acquiring cultural knowledge for counselors in training: A multifaceted approach. Counselor Education and Supervision, Sept:61-71.

PONTEROTTO, J.G. \& CASAS, J.M. 1987. In search of multicultural competence within counselor education programs. Journal of Counseling and Development, 65:430-434.

PRIEST, R. 1994. Minority supervisor and majority supervisee: Another perspective of clinical reality. Counselor Education and Supervision, 34:152-157.

RYAN, A.S. \& HENDRICKS, C.O. 1989. Culture and communication: Supervising the Asian and Hispanic social worker. The Clinical Supervisor, 7:27-40.

VARGAS, L.A. 1989. Training psychologists to be culturally responsive: Issues in supervision. Paper presented at the annual meeting of the American Psychological Association, New Orleans.

WESSLER, R.L. \& ELLIS, A. 1983. Supervision in counseling: Rational-emotive therapy. The Counseling Psychologist, 11:43-49.

Prof Ashraf Kagee, Department of Psychology, Stellenbosch University, Stellenbosch, South Africa. 